$\xi=$

\title{
Evaluation of antimycobacterial rhamnolipid production from non-cytotoxic strains of Pseudomonas aeruginosa isolated from rhizospheric soil of medicinal plants
}

\author{
Alok K Mishra*, Rikesh K Dubey, Shivraj M Yabaji, Swati Jaiswal \\ Division of Microbiology and Academy of Scientific and Innovative Research, CSIR-Central Drug Research Institute, Lucknow 226031 \\ *Corresponding author E-mail:alok.csir@gmail.com
}

\begin{abstract}
Rhamnolipids (RLs) are the bacterial derived biosurfactants and known for a wide range of industrial and therapeutic applications. They exhibit potent anti-bacterial activity against various gram positive, gram negative and acid fast bacteria including Mycobacterium tuberculosis. Since, Pseudomonas is one of the largest known genuses containing a variety of rhamnolipid producing strains. Therefore, in this study, we selectively isolated the Pseudomonas aeruginosa strains from the rhizospheric soil of the Indian plants of medicinal value, e.g. Azadirachta Indica and Ficus spp., and evaluated them for their natural ability to produce antibacterial rhamnolipids. The bacteria were identified on the basis of $16 \mathrm{~s}$ rRNA sequencing and biochemical characterization. Among 33 of $P$. aeruginosa isolates from different soil samples, four isolates showed potent inhibitory activity against methicillin resistant Staphylococcus aureus (MRSA) and fast grower mycobacterial spp. The inhibitory potential of the isolates was found to be correlated with their ability to produce RLs in the medium. The industrial viability of the strains was assessed on the basis of cytotoxicity determining alternative allele, exoS/exoU and cell mediated cytotoxicity against murine macrophages $\mathbf{J} 774$.1. The newly isolated strains harbor exoS allele and exhibits lower cell mediated cytotoxicity on macrophage cell line as compared to the clinical strains PA-BAA-427 and PA-27853 used as a control in this study.
\end{abstract}

Keywords: Mycobacteria; Pseudomonas aeruginosa; Rhamnolipids; Rhizospheric soil

\section{Introduction}

Despite impressive therapeutic progresses in the battle against infections, microorganisms are still a threat to mankind(Chiang et al., 2010; Kolyva and Karakousis, 2012). With hundreds of antibacterial molecules, major concerns remain about the emergence of resistant and multidrug-resistant pathogens (Strateva and Yordanov, 2009; Chiang et al., 2010). Mycobacterium tuberculosis is a devastating pathogen and continues to be one of the leading causes of deaths worldwide (Chiang et al., 2010; Sharma and Tyagi, 2007). The rapid emergence of drug resistance in mycobacteria exacerbate the problem several folds. Therefore, there is a constant need to search the new antibacterials to eradicate this deadly pathogen. The bacterial derived natural biosurfactant such as rhamnolipids have been studied for their antibacterial activity against a wide range of pathogenic bacteria including Mycobacterium tuberculosis (Abalos et al., 2001). Since mycobacteria posses uniquely impermeable cell wall, therefore, a large arsenal of chemically synthesized antibacterial molecules remains ineffective against this pathogen (Barry and Mdluli, 1996). However, owing to the biosurfactant nature the bacterial derived rhamnolipids (RLs) might be the effective antibacterial candidates against mycobacteria. The opportunistic pathogens like Pseudomonas aeruginosa and Bacillus spp. are the best known producers of such kind of anti bacterial rhamnolipis. Pseudomonas aeruginosa strains produce a variety of mono- and di-rhamnolipids (Abalos et al., 2001; Irie et al., 2005; Soberón-Chávez et al., 2005a, 2005b). The rhamnolipids are basically the conjugates of rhamnose sugar with a highly variable fatty acid chains (Nguyen and Sabatini,
2011).These are produced in the form of secondary metabolites and work as virulent factors (McClure and Schiller, 1992). Although the exact mechanism of the antibacterial property of rhamnolipids is not clearly understood, however, the bacterial killing activity of the conjugate molecules has been anticipated to be related to their membrane lysing activity. Pseudomonas aerugino$s a(\mathrm{PA})$ is also known for its inter-strain variations and to produce a large number of secondary metabolites of clinical as well as industrial importance (Gross and Loper, 2009; Soberón-Chávez et al., 2005b). The rhizospheric strains of Pseudomonas have been extensively studied with respect to their plants growth promoting ability ( Walker et al., 2004; Ahemad and Khan, 2010). The organism basically provide inorganic nutrition to the plant through its inherent metal acquisition by forming siderophore and phosphate solubilization capabilities (Ahemad and Khan, 2010; Cox and Adams, 1985; Miethke and Marahiel, 2007). Besides this, some of the strains of Pseudomonas are known to promote plant growth by suppressing plant-pathogenic micro-organisms (Mishra and Arora, 2012; Preston, 2004), whereas some other strains inhibit plant growth and leads to the appearance of disease symptoms such as canker, necrosis, rot and gal etc. (Höfte and Vos, 2006; Walker et al., 2004). Interestingly, these variation can be observed within the species (Wehmhöner et al., 2003, Dettman et al., 2013). However, the plant associated non virulent strains of pseudomonas having inhibitory activities against 'human pathogens' are largely unexplored. Thus in the present study, we exercised the exploration of plant associated soil bacteria producing antibacterials and evaluated them for their natural ability to produce rhamnolipids. The bacteria were isolated from the rhizo- 
spheric soils of Indian plants of medicinal importance such as Azadirachta indica and Ficus religiosa.

\section{Material and methods}

\subsection{Isolation and cultivation of soil bacteria}

The soil samples of $1.0 \mathrm{~g}$ each were collected from the rhizospheric regions of a medicinal plant Azadirachta indica and Ficus religiosa. The samples were agitated vigorously in $100 \mathrm{ml}$ of deionized MQ water with a few drops of Tween-80. After letting the soil particles settled for $1 \mathrm{~h}, 1.0 \mathrm{ml}$ of each supernatant was serially diluted and $100 \mu \mathrm{l}$ of the $10^{-5}$ and $10^{-6}$ diluted fractions were spread on agar plate containing native soil extract by spreading method and incubated for $3-4$ days at $37^{\circ} \mathrm{C}$. The soil extract added to agar medium has been proved to be the valuable for the isolation of soil bacteria in higher plate counts (Gilmour, 1951). The soil extract medium was prepared with extract of native soil, with the notion that the required nutrients of bacteria are supposed to be present in their native microenvironment. One hundred gram of soil was collected additionally from the same place where the soil samples for bacterial isolation were collected. The soil was agitated vigorously in 1 liter of de-ionised MQ water. A few drops of Tween-80 were added. After letting the soil particles get settled overnight, the clear supernatant was autoclaved and used in preparing the modified Luria Broth Agar medium (Tryptone $10 \mathrm{~g} / \mathrm{l}$ Yeast extract $5 \mathrm{~g} / \mathrm{l}, \mathrm{NaCl} 10 \mathrm{~g} / \mathrm{l}$ with $1.5 \%$ Agar) containing soil extract.

\subsection{Screening for antibacterial activity}

The isolated bacterial colonies obtained at native soil extract agar medium with distinct morphological characteristics were transferred on to the LB agar plates. The colonies obtained on to the agar plates were sub-cultured in LB broth (Tryptone $10 \mathrm{~g} / \mathrm{l}$, Yeast Extract $5 \mathrm{~g} / \mathrm{l}, \mathrm{NaCl} 10 \mathrm{~g} / \mathrm{l}$ in de-ionized $\mathrm{H}_{2} \mathrm{O}, \mathrm{pH} 7.5$ ) overnight and streaked onto a lawn of growing $S$. aureus cells on to the nutrient agar plates. After $12 \mathrm{~h}$ of incubation at $37^{\circ} \mathrm{C}$, visible clearing zones indicated the antibacterial activity.

\subsection{Strain identification}

The genomic identity of the isolates was determined by sequencing its 16s rRNA gene (Drancourt et al., 2000). $1.0 \mathrm{ml}$ of bacteria culture was pelleted down at $4^{\circ} \mathrm{C}$ and at $4000 \times \mathrm{xg}$ in $1.5 \mathrm{ml}$ micro centrifuge tube. The pellet was re-suspended in $200 \mu \mathrm{l}$ of deionized water, sonicated using 2-3 pulses and kept in boiling water for 5 minutes. Centrifuged at $14000 \mathrm{xg}$ and the supernatant was used as template to amplify the 16S rRNA gene, using PCR Master Mix and the universal primers E8F and U1510R (Table.1)(Baker et al., 2003; Woese and Fox, 1977). The thermocycler parameters included 35 cycles of $95^{\circ} \mathrm{C}$ for $30 \mathrm{~s}$, annealing for 30 s at $45^{\circ} \mathrm{C}$, extension at $72^{\circ} \mathrm{C}$ and final extension of $72^{\circ} \mathrm{C}$ for 10 min. The amplified DNA fragment was sequenced by Sanger sequencing (Xcelris genomics, Ahmadabad, India). The resultant sequences were compared to known bacterial sequences in the NCBI (www.ncbi.nlm.nih.gov/) using basic local alignment search tool (BLAST).

Table 1: List of primers used in the study

\begin{tabular}{|c|c|c|c|}
\hline $\begin{array}{l}\text { S. } \\
\text { No. }\end{array}$ & Gene & Primers sequences & References \\
\hline \multicolumn{4}{|c|}{ Primers for Strain Identification } \\
\hline 1. & $\begin{array}{l}16 \mathrm{~s} \\
\text { rDNA }\end{array}$ & $\begin{array}{l}\text { E8F - AGAGTTGATCCTGGCTCAG } \\
\text { U1510R- GGT TAC CTTGTTAC- } \\
\text { GACT T }\end{array}$ & $\begin{array}{l}\text { (Baker et al., } \\
\text { 2003) }\end{array}$ \\
\hline \multicolumn{4}{|c|}{ Primers for detection of Exotoxin producing strains } \\
\hline 1. & exoU & $\begin{array}{l}\text { F'-GCTAAGGCTTGGCGGAATA } \\
\text { R'-AGATCACACCCAGCGGTAAC }\end{array}$ & $\begin{array}{l}\text { (Lin et al., } \\
2006 \text { ) }\end{array}$ \\
\hline 2. & exoS & $\begin{array}{l}\text { F'-ATGTCAGCGGGATATCGAAC } \\
\text { R'-CAGGCGTACATCCTGTTCCT }\end{array}$ & \\
\hline
\end{tabular}

\subsection{Biochemical tests}

The biochemical characterization of bacteria was done by using biochemical identification test kit (KB002, HiAssorted ${ }^{\mathrm{TM})}$ purchased from HiMedia. The well isolated colonies of the bacteria were obtained on Muller Hilton agar plate and inoculated in $5.0 \mathrm{ml}$ brain heart infusion broth (BHIB) at $37^{\circ} \mathrm{C}$ for 4-6 h until OD of the innocula reached up to 0.1 at $0.5 \mathrm{McFarland}$ standards. The tests were performed as prescribed in the user's manual provided with the kit and the results were compared with the standards result interpretation chart. The species was confirmed by using, identification index for gram negative rods, supplied with the Kit. The two clinical isolates of American type culture collection, PA (ATCC BAA-427 and ATCC 27853) were taken as control.

\subsection{ExoS/exoU allele typing}

The cytotocxicity determining alternative alleles were amplified from the genomic DNA of the newly isolated bioactive strains of Pseudomonas aeruginosa. The DNA sequence of the primers used for the RAPD and exoS/exoU allele typing are given the Table.1.

\subsection{Measurement of RLs production}

The quantification of RLs production in bacterial culture supernatants was done by orcinol test as described earlier ( $\mathrm{H}$. Rashedi and E. Jamshidi, 2005; Li et al., 1984; Rahman et al., 2002). Briefly, $100 \mu \mathrm{l}$ of culture supernatant was mixed with $1.9 \mathrm{ml}$ of orcinol solution containing $100 \mathrm{mg}$ orcinol in $50 \% \mathrm{H}_{2} \mathrm{SO}_{4}$, and then boiled for $30 \mathrm{~min}$. The samples were cooled at room temperature and analysed spectrophotometrically at $421 \mathrm{~nm}$. RL concentrations were calculated from standard curves prepared with L-rhamnose (Sigma Aldrich, USA) and expressed as rhamnose equivalents (in $\mathrm{mg} / \mathrm{ml}$ )

\subsection{Luciferase activity inhibition assay}

The M. smegmatis expressing luciferase gene under Hsp60 promoter in pMV361 vector was used for the evaluation of the inhibitory activity of bioactive strains. The log phage culture of $M$. smeg:Lux was inoculated in Sautaon's media in a dilution of $10^{2}$ bacilli per ml. The cells were treated with $100 \mu \mathrm{l}$ of culture supernatants of each the isolated bacterial containing RLs. The readings were taken by luminometer (Sririus L, Berthold). The relative luminescence units (RLU) were plotted for each sample.

\subsection{Cell culture and cytotoxicity assay}

The macrophage cell line J774.1 was cultured at $37^{\circ} \mathrm{C}$ and $5 \%$ $\mathrm{CO}_{2}$ in RPMI-1640 medium ( $2 \mathrm{mM}$ L-glutamine, $10 \mathrm{mM}$ HEPES, $1 \mathrm{mM}$ sodium pyruvate, $4.5 \mathrm{~g} / \mathrm{L}$ glucose and $1.5 \mathrm{~g} / \mathrm{L}$ sodium bicarbonate) (Sigma-Aldrich), supplemented with $10 \%$ heat inactivated fetal calf serum (Gibco). The cells having density of $5 \times 10^{5}$ cells $/ \mathrm{ml}$ was seeded in tissue culture plates. The cell suspensions of log-phase bacteria were prepared by vortexing in presence of sterile glass beads and passing through a 26 gauge needle and used for macrophage infection $1.0 \times 10^{6}$ and $1.0 \times 10^{8}$ as described. The relative cytotoxicity of the isolates was determined by quantifying the lactate dehydrogenase (LDH) released upon cell death death, using cytotoxity assay kit (cytotox 96, Promega). The cytotoxicity was tested on murine derived macrophage cell line J774A.1 as described previously(Decker and Lohmann-Matthes, 1988).

\section{Results}

3.1. Isolation and identification of $P$. aeruginosa strains producing antimicrobial rhamnolipids 
A large number of colonies were obtained on the nutrient agar plate upon dilution plating of soil samples. Since, $P$. aeruginosa strains can be easily recognized by their characteristic blue green pigmentation and positive citrate agar test. Therefore, for selective isolation of $P$. aeruginsa, the colonies obtained on the nutrient agar plate were transferred on to the citrate agar plates. The colonies showing positive citrate agar test were sub-cultured in Muller Hilton media. Finally, 33 colonies of $P$. aeruginosa strains were obtained and screened for the antibacterial activity against $E$. coli, $S$. aureus(MSSA), S. aureus (MRSA), P. aeruginosa POAl, M. smegmatis. M. fortuitum and M. abscessus. Notably, all the isolated PA strains were found to be exclusively active against both methicillin sensitive (MSSA) and methicllin resistant S. aureus (MRSA), whereas none of them showed inhibition of any of the gram negative bacterial spp. E. coli and $P$. aeruginosa POA1. However, interestingly only four strains, provisionally annotated as PA-10, PA-12, PA-20, and PA-22 exhibited the inhibitory activity against the three mycobacterial strains used in the study (Table.2). The four bacterial isolates active against acid fast bacteria (Fig.S1) were further, identified at genetic level by 16s rRNA sequencing. All the four isolates share $99 \%$ identity of the partial sequences of $16 \mathrm{~s}$ rRNA (1000bp) with that of typical Pseudomonas aeruginosa strains. The two clinical stains of $P$. aeruginosa; ATCC BAA-427 and PA ATCC 28753 were used as controls for identification and differential characterization of the soil isolates. The antibacterial activity of the two control strains was also tested. More interestingly, the control clinical strain strains showed zone of clearance against $S$. aureus and MRSA. However, none of them had any inhibitory activity against the mycobacterial species tested (Fig.S1). Therefore, we choose only the four isolates for further characterization and purification of the rhamnolipids.

\subsection{Biochemical characterization}

In biochemical characteristics, all the four bioactive isolates were found to be gram negative rods. They showed positive tests for catalase, oxidase and urease. However, some differences in the biochemical characteristics were also observed viz, PA-10 and PA-22 did not fermented glucose but utilized nitrate whereas PA12 and PA-22 fermented glucose in the culture medium, but no nitrate reduction was detected. Moreover, PA-10 also did not utilize arabinose but, fermented lactose and sorbital (Table. 3). Since, nitrate utilization is not the characteristic of a typical PA, therefore, further biochemical characterization and genetic analysis was needed to confirm the species identity of PA-10 and PA-22. The inter strain variation of pigmentation characteristics and colony morphology was also observed in the isolates, PA -10 showed highest pigmentation (yellow-green) in the Muller -Hilton medium after a 36 hour of incubation at $37^{\circ} \mathrm{C}$ as compared to the three other isolates (Fig.S2). The pigmentation of PA-22 was yellow till 36 hour and turned red after 40 hour. Unlikely, the clinical isolates showed deep blue green pigmentation at the same conditions. The blue color of the bacterial culture is attributed to the production of a toxic pigment pyocyanin. The results indicated that the rhizospheric soil isolates produce relatively low level of pyocyanin than the clinical strains. The differences in colony morphology were also observed in terms of opacity, surface texture, elevation and shape of margin etc. Although, PA-10, 20, and 22 shared the same colony characteristics such as rough surface, wavy margin and raised elevation with opaque colonies, however with difference in pigmentation. Whereas, PA-12 had some distinct characteristics such as smooth surface and entire margin etc. The colony characteristics of the clinical isolates were did not match with any of the soil isolates.

Table 2: Screening of the antibacterial property of rhizospheric isolates against gram positive, gram negative and acid fast bacterial strains, Ec; E.coli, SA Staphylococcus aureus, MRSA; Methicillin resistant Staphylococcus aureus, POA1; Pseudomonas aeruginosa POA1, Ms; M.smegmatis, Mf; M. fortuitum, Mab; M. abscessus.

\begin{tabular}{|c|c|c|c|c|c|c|c|}
\hline Isolates & $E c$ & $S A$ & MRSA & POA1 & $M s$ & $M f$ & $M a b$ \\
\hline \multicolumn{8}{|l|}{ PA-1 } \\
\hline \multicolumn{8}{|l|}{ PA-2 } \\
\hline \multicolumn{8}{|l|}{ PA-3 } \\
\hline \multicolumn{8}{|l|}{ PA-4 } \\
\hline \multicolumn{8}{|l|}{ PA-5 } \\
\hline \multicolumn{8}{|l|}{ PA-6 } \\
\hline \multicolumn{8}{|l|}{ PA-7 } \\
\hline \multicolumn{8}{|l|}{ PA-8 } \\
\hline \multicolumn{8}{|l|}{ PA-9 } \\
\hline \multicolumn{8}{|l|}{ PA-10 } \\
\hline \multicolumn{8}{|l|}{ PA-11 } \\
\hline \multicolumn{8}{|l|}{ PA-12 } \\
\hline \multicolumn{8}{|l|}{ PA-13 } \\
\hline \multicolumn{8}{|l|}{ PA-14 } \\
\hline \multicolumn{8}{|l|}{ PA-15 } \\
\hline \multicolumn{8}{|l|}{ PA-16 } \\
\hline \multicolumn{8}{|l|}{ PA-17 } \\
\hline \multicolumn{8}{|l|}{ PA-18 } \\
\hline \multicolumn{8}{|l|}{ PA-19 } \\
\hline \multicolumn{8}{|l|}{ PA-20 } \\
\hline \multicolumn{8}{|l|}{ PA-21 } \\
\hline \multicolumn{8}{|l|}{ PA-22 } \\
\hline \multicolumn{8}{|l|}{ PA-23 } \\
\hline \multicolumn{8}{|l|}{ PA-24 } \\
\hline \multicolumn{8}{|l|}{ PA-25 } \\
\hline \multicolumn{8}{|l|}{ PA-26 } \\
\hline \multicolumn{8}{|l|}{ PA-27 } \\
\hline \multicolumn{8}{|l|}{ PA-28 } \\
\hline PA-29 & & & & & & & \\
\hline PA-30 & & & & & & & \\
\hline PA-31 & & & & & & & \\
\hline PA-32 & & & & & & & \\
\hline PA-33 & & & & & & & \\
\hline
\end{tabular}


Table 3: Biochemical characteristics of the newly isolated strains and comparison with two previously characterized clinical strains.

\begin{tabular}{|c|c|c|c|c|c|c|c|}
\hline S.No. & Characteristics & $\begin{array}{l}\text { P.aeruginosa ATCC } \\
\text {-BAA- } 427 *\end{array}$ & $\begin{array}{l}\text { P.aeruginosa ATCC } \\
27853^{*}\end{array}$ & $\begin{array}{l}\text { P. aeruginosa } \\
\text { KR265319 } \\
\text { PA-10 }\end{array}$ & $\begin{array}{l}\text { P. aeruginosa } \\
\text { KT266560 } \\
\text { PA-12 }\end{array}$ & $\begin{array}{l}\text { P. aeruginosa } \\
\text { KT266561 } \\
\text { PA-20 }\end{array}$ & $\begin{array}{l}\text { P. aeruginosa } \\
\text { KT266562 } \\
\text { PA-22 }\end{array}$ \\
\hline 1. & Gram staining & -ve & -ve & -ve & -ve & -ve & -ve \\
\hline 3. & Lysine & - & - & - & - & - & - \\
\hline 4. & Ornithine & - & - & - & - & - & - \\
\hline 5. & Urease & + & + & + & + & + & + \\
\hline 6. & Phenylalanine deamination & + & + & + & + & + & - \\
\hline 7. & Nitrate reduction & - & - & + & - & - & + \\
\hline 8. & $\mathrm{H}_{2} \mathrm{~S}$ production & - & - & - & - & - & - \\
\hline 9. & Glucose & + & + & - & + & + & - \\
\hline 10. & Adonitol & - & - & - & - & - & - \\
\hline 11. & Lactose & + & - & - & - & - & - \\
\hline 12. & Arabinose & + & + & - & + & + & + \\
\hline 13. & Sorbitol & - & - & - & - & - & - \\
\hline
\end{tabular}

(+) Positive reaction, (-) Negative Reaction (*) Control strains

\subsection{Submission of sequence to genbank and accession number}

The 16s rRNA sequences of the four newly isolated strains PA-10, PA-12, PA-20 and PA-22 were submitted in Genebank ( http://www.ncbi.nlm.nih.gov/BankIt) with the accession numbers KR265319, KT266560, KT266561 and KT266562 respectively.

\subsection{Evaluation of isolates for rhamnolipids production and correlation with their bacterial inhibitory activity}

Rhamnolipid production was evaluated by quantifying the per $\mathrm{ml}$ production of RLs using orcinol assay (described in materials and methods section). The RL production was measured at $6 \mathrm{~h}$ and $12 \mathrm{~h}$. We observed the higher production of RLs at stationary phase of the growth as compared to the late log phase. However, among the four bioactive rhizospheric isolates, PA-22 was found to be the best producer of RLs at the given experimental conditions (Fig 1). Further, to confirm that the antibacterial activity observed in the isolates is attributed to the RL production, we assessed the bacterial inhibitory potential of the culture supernatants. The relative bacterial inhibitory potential of the samples was tested by using recombinant $M$. smegmatis cell expressing luciferase gene. The maximum inhibitory activity per ml culture supernatant was observed in the PA-22 which is positively correlated with the higher RLs production in PA-22 (Fig. 1). Therefore, in our study PA-22 (KT266562) was found to be the best producer at the given conditions. However, the growth media and other abiotic factors such as temperature, light and aeration are needed to be optimized for the further evaluation of the RLs production potential of the isolates.

\subsection{Exou /exos typing for determination of cytotoxicity at genetic level}

PCR detection of exo $U$ and exoS genes is widely used for typing of toxic and non toxic Pseudomonas strains respectively(Diaz and
Hauser, 2010; Lin et al., 2006; Sato and Frank, 2004; Shaver and Hauser, 2004). Therefore, in order to assess the industrial viability of the strains, producing potent anti-mycobacterial rhamnolipids were tested for the presence or absence of mutually exclusive exoS/exoU allelels. For genetic typing of cytotoxicity the ex$o S / E x o U$ gene segments was amplified from the genomic DNA of the isolates. The two clinical strains PA-BAA-427 and PA-27853 were used as control. The genetic typing revealed that all the four soil isolates harbor exoS allele, which indicates that the isolated bioactive strains are non cytotoxic. However, among two clinical strains only PA-BAA-427 was found to be exoU positive whereas PA-27853 was exoS positive (Fig.2)

\subsection{Cell mediated cytotoxicity against murine derived macrophage cell line $\mathbf{J 7 7 4 . 1}$}

The soil isolates PA-10(exoU $\left.U^{-}\right)$, PA-12(exoU $)$, PA-20(exoU $\left.U^{-}\right)$, and PA-22 (exoU) exhibited the lower cell mediated cytotoxicity (expressed as percentage of LDH release) as compared to the clinical isolates after $24 \mathrm{~h}$ of infection on macrophage $\mathbf{J} 774.1 \mathrm{cell}$ line. The level of cytotoxicity of all the strains was found to be cell density dependent (Fig.3). The cells infected with bacterial culture containing $10^{8} \mathrm{cfu} / \mathrm{ml}$ released more LDH than that of infection with $10^{6} \mathrm{cfu} / \mathrm{ml}$. P. aeruginosa BAA-427(exoU $\left.{ }^{+}\right)$led to higher lysis of the J774.1 cells than $P$. aeruginosa 28753 (exoU ${ }^{-}$) at the two bacterial concentrations (Fig.3). However, the higher LDH release in exo $U$ negative PA-28753 as compared to the exoU negative suggests the exoU independent cytotoxicity in the strain therefore; further investigation is needed to identify the other factors responsible for the cytotoxicity in exoU negative strains. The cell monolayers after infection with bacterial inocula $1.0 \times 10^{8} \mathrm{cfu} / \mathrm{ml}$ were observed under light microscope. A slight cell detachment was detectable upon infection with PA-10 and PA-12, while more cells were detaching after infection with PA-20 and PA-22. Infection with clinical strains $P$. aeruginosa-BAA-427 and $P$. aeruginosa 28753 led to $\sim 80$ and $\sim 90 \%$ disappearance of the organized cell monolayer respectively (Fig.4). 
(a)

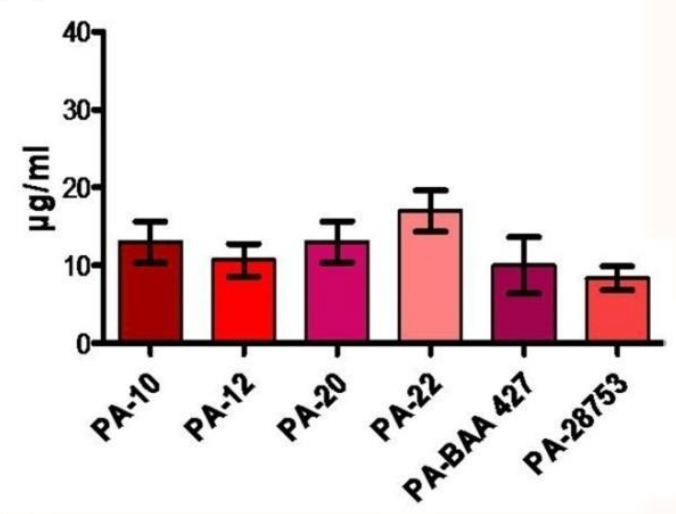

(c)

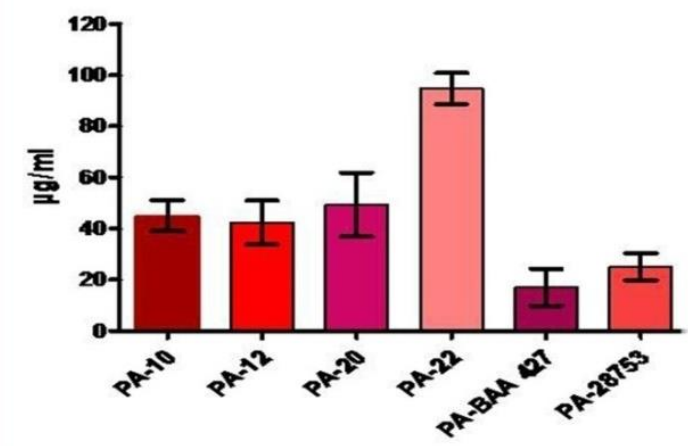

(b)

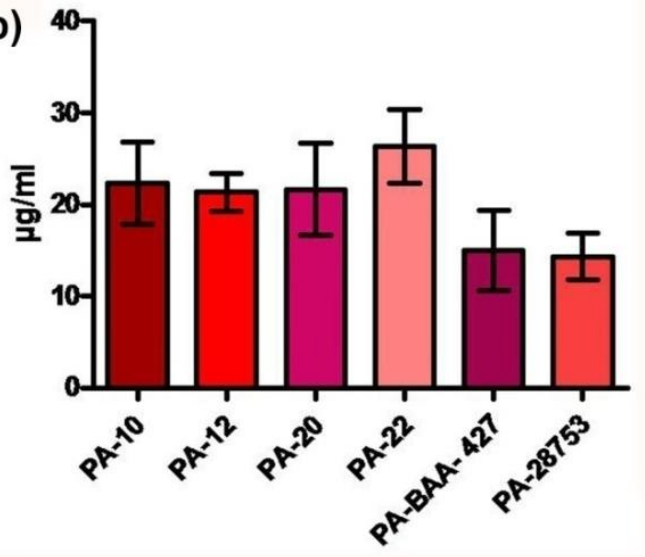

(d)

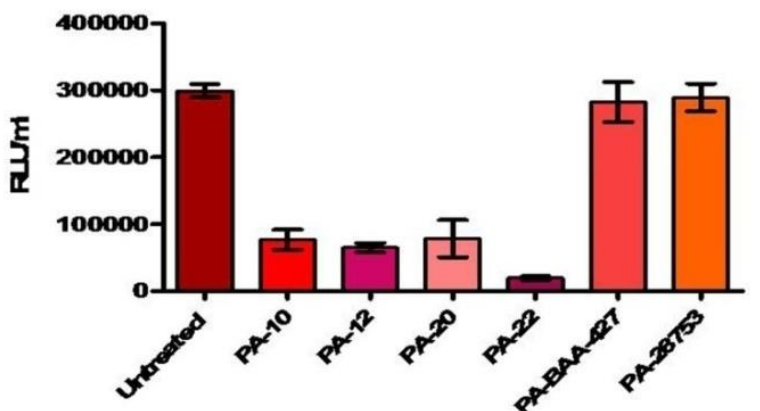

Fig. 1: RLs production in the bacterial lysates; The formation of blue colored complex with orcinol was measured spectrophotomerically at 421 nm. The standard curve for the purified rhamnolipid was used for the quantification of the concentrations of the unknown in terms of rhamnose equivalents (mg/ml). (a) Per ml production of RLs in 3hours (b) 6 hours (c) 24 hours culture, Results are the mean +/- SEM of three independent experiments (d) Anti- mycobacterial activity (inhibition of bacteria) per $\mathrm{ml}$ of culture supernatant measured in terms of relative luminescence units (RLU).

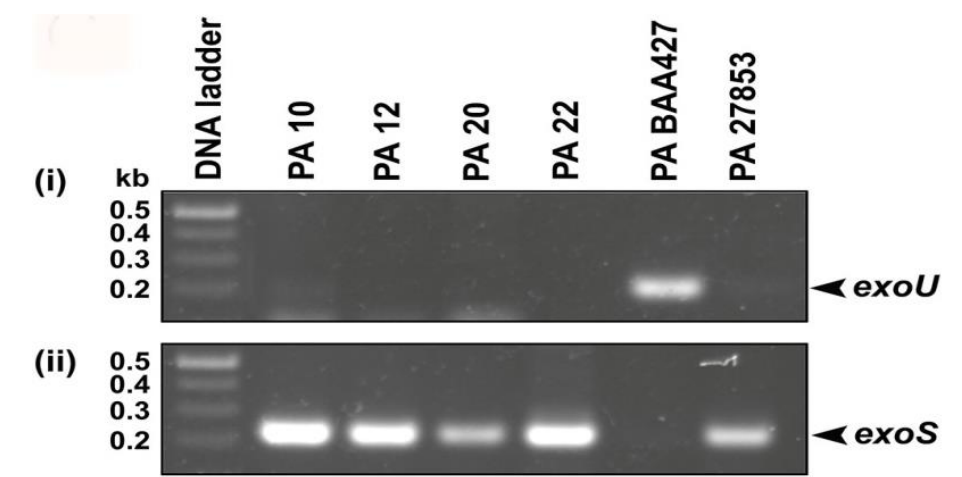

Fig. 2: PCR amplifications to detect the presence and/or the absence of exoS/exoU alleles; the amplified PCR products were visualized on the agarose gel.

(a)

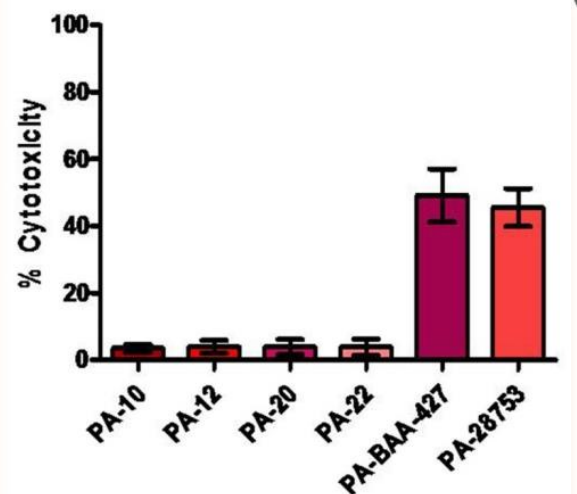

(b)

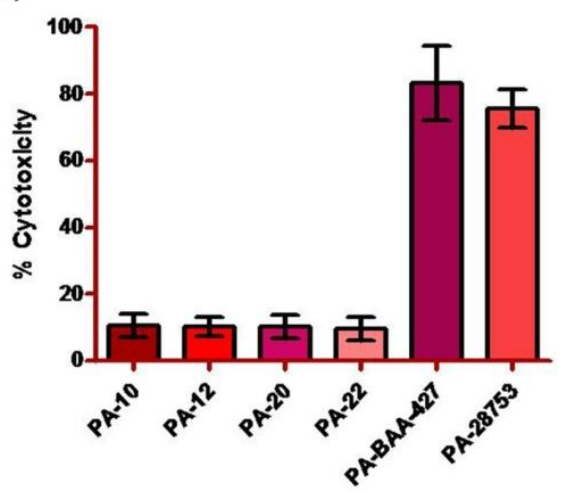

Fig. 3: Cytotoxicity was determined by LDH release assay after $24 \mathrm{~h}$ of infection. (a) Percentage cytotoxicity of the isolates on J774.1 cells with the infection frequency of $1.0 \times 10^{6}$ (b) Percentage cytotoxicity of the isolates on J774.1 cells with the infection frequency of $1.0 \times 10^{8}$. Results were calculated as the mean values (+/- SEM) of three independent experiments. 

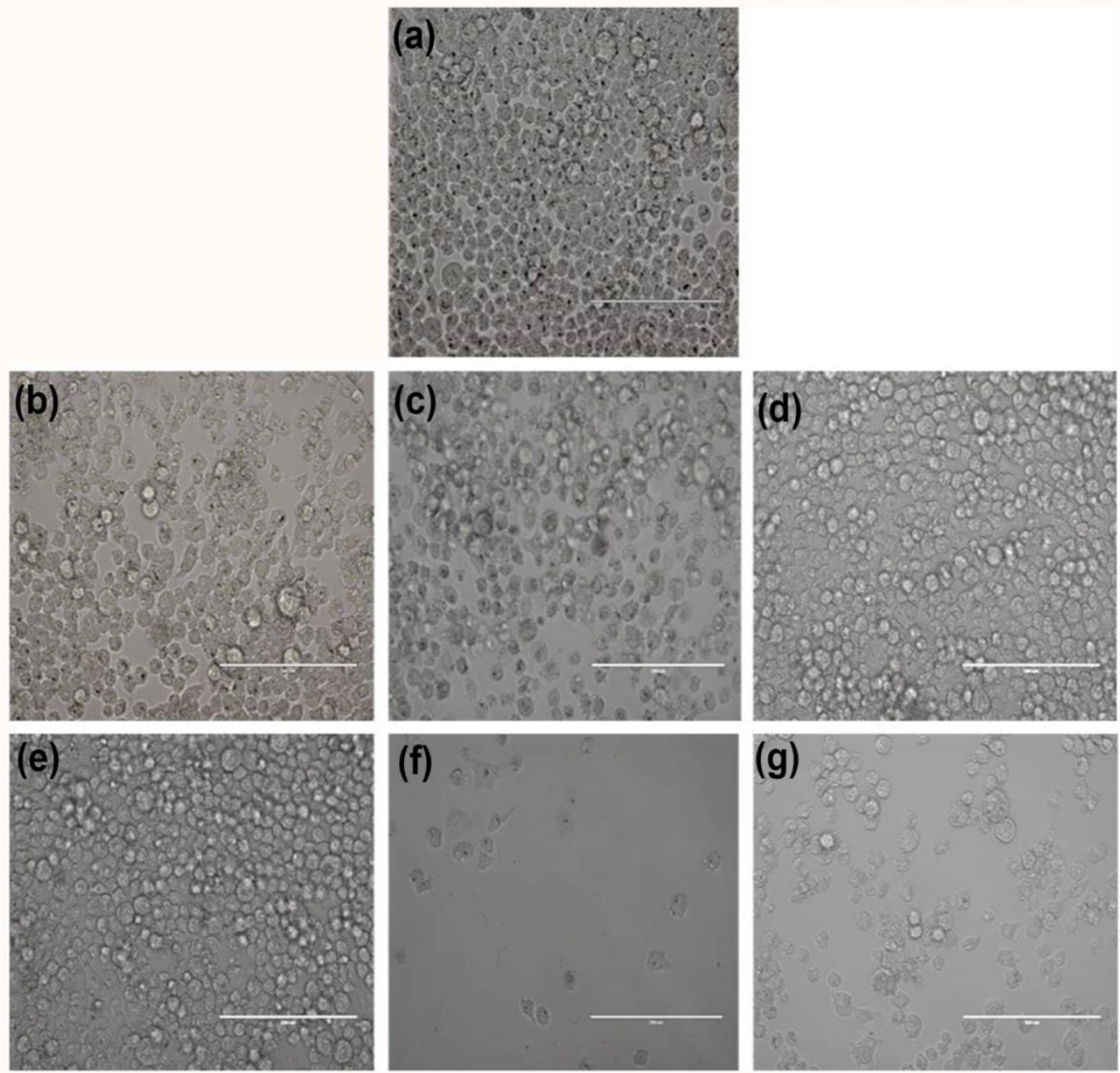

Fig. 4: Effects of on the morphological aspect of J774.1 cells monolayer compared to a non-infected monolayer. (a) Uninfected (b) PA-10, (c) PA-20, (d) PA-20, (e) PA-22 (f) PA-BAA-427 (g) PA-28753. The figure only shows the results obtained after $24 \mathrm{~h}$ of infection with a concentration of $10^{8} \mathrm{CFU} / \mathrm{ml}$ Scale bar $=200 \mu \mathrm{m}$.

\section{Discussion}

Pseudomonas aeruginosa (PA) has tremendous ability to modulate its genome to better respond to its habitat conditions, which consequently give rise to the high inter-strain variability and to produce the strain specific secondary metabolites (Gross and Loper, 2009; Mathee et al., 2008). PA strains are widely known to produce surface-active molecules of glycolipidic nature called rhamnolipids (Abalos et al., 2001). Rhamnolipids have potential biotechnological applications due to their unique physiochemical properties such as emulsifying, solubilizing and metal sequestering activity etc. (Abalos et al., 2001; Irie et al., 2005; SoberónChávez et al., 2005b). The antibacterial properties of rhamnolipids have been reported against a wide range of gram positive and gram negative pathogenic bacteria(Magalhães and Nitschke, 2013). In this study, four new bacterial strains showing potent anibacterial activity against mycobacterial spp, were evaluated for their natural ability to produce rhamnolipids. The isolates were identified as Pseudomonas aeruginosa on the basis of morphological, biochemical and genetic characteristics. However, some atypical characteristics were observed in two of the strains provitionally named PA-10 and PA-22. Notably, both the strains reduced nitrate but did not utilized glucose in medium, which is not the chracteristics of a typical PA strains. Nevertheless, on the basis of mutilocus sequencing typing (MLST), both the strains were declared as the novel sequence types (ST) of PA rather new specieses. Once the genetic and biochemical strain identification was done two clinical laboratory strains of PA (ATCC-BAA-427 and ATCC 27853) of American type culture collection (ATCC) were taken for comparative analysis of bacterial characteristics, and the assesment of antibiosis. The clinical strains also showed zone of inhibition on the growing lawn of $S$. aureus. However, they were inactive against all the three fast growing mycobacterials species taken for the screening i.e. M. smegmatis, M. fortuitum and M. abscessus. The strains of P. aeruginosa harbor the genes for the four effector proteins; exoT, exoY, exoS and exoU, which are translocated from its type III secretion system, the secretion of these effector proteins determines the cytotoxicity of the strain during infection (Diaz and Hauser, 2010). However, among these proteins the presence of exoS and exoU is a mutually exclusive event as both the alleles are seldom present in one strain (Lin et al., 2006; Shaver and Hauser, 2004). The strains harboring exoU allele are relatively more cytotoxic and invasive than the alleles having alternative allele, exoS (Lin et al., 2006; Sato and Frank, 2004). In this study all the four new isolates belonged to the exoS allelelic group, therefore, the possibility of antibacterial activity against the mycobacteria due to the product of the cytotoxic gene can be ruled out. Futher the cytotoxicity data showed a positive correlation with the alleles with exception of PA-22. A clinical strain (control) PA-BAA-427, harbors exoU allele and showed more than $80 \%$ cytotoxicity at the infection frequency of $1.0 \times 10^{8}$ whereas PA-ATCC 27853 with exoS allele showed less than $9 \%$ cytotoxicity at the same MOI.

\section{Conclusion}

Rhamnolipids are the natural biomolecules and known for their tremendous industrially as well as clinical applicablility . RLs are produced by the various strains of genus pseudomonas and bacillus In this study the PA strains showing inhibitory activity against mycobacterial strains were isolated from rhizospeheric 
soils and partially characterized for their capabilities to be employed for the scale up production of RLs. Since, Pseudomonas aeruginosa is an opportunistic pathogen, therefore, for commercial production of rhamnolipids from PA, the industrial viability of the strains is primarily required to be tested. The Newly isolated strain PA-10 with the maximum efficacy and lower cytotoxicity can be futher explored for its industial utility.

\section{Acknowledgements}

We thank Dr. KKS for proving laboratory facility and constant encouragement. Financial supports by Open Source Drug Discovery (CSIR) and Department of Biotechnology are also acknowledged. We also thank Dr. P. K. Shukla for providing strains of PA and Dr. Sidharth Chopra for providing the strains and antibiotics.

\section{References}

[1] Abalos, A., Pinazo, A., Infante, M.R., Casals, M., García, F. Manresa, A. (2001) Physicochemical and antimicrobial properties of new rhamnolipids produced by Pseudomonas aeruginosa AT10 from soybean oil refinery wastes. Langmuir 17(5), 1367-71, http://dx.doi.org/10.1021/la0011735.

[2] Ahemad, M., Khan, M.S. (2010) Phosphate-solubilizing and plantgrowth-promoting pseudomonas aeruginosa PS1 improves greengram performance in quizalafop-p-ethyl and clodinafop amended soil. Arch. Environ. Contam. Toxicol. 58(2), 361-72, http://dx.doi.org/10.1007/s00244-009-9382-z.

[3] Baker, G.C., Smith, J.J., Cowan, D.A. (2003) Review and re analysis of domain-specific $16 \mathrm{~S}$ primers. J. Microbiol. Methods, 541-55, http://dx.doi.org/10.1016/j.mimet.2003.08.009.

[4] Barry, C.E., Mdluli, K. (1996) Drug sensitivity and environmental adaptation of mycobacterial cell wall components. Trends Microbiol., $\quad 275-81, \quad$ http://dx.doi.org/10.1016/0966842X(96)10031-7.

[5] Chiang, C.-Y., Centis, R., Migliori, G.B. (2010) Drug-resistant tuberculosis: past, present, future. Respirology 15(3), 413-32, http://dx.doi.org/10.1111/j.1440-1843.2010.01738.x.

[6] Cox, C.D., Adams, P. (1985) Siderophore activity of pyoverdin for Pseudomonas aeruginosa. Infect. Immun. 48(1), 130-8, Doi: 00199567/85/040130-09\$02.00/0

[7] Decker, T., Lohmann-Matthes, M.L. (1988) A quick and simple method for the quantitation of lactate dehydrogenase release in measurements of cellular cytotoxicity and tumor necrosis factor (TNF) activity. J. Immunol. Methods 115(1), 61-9, http://dx.doi.org/10.1016/0022-1759(88)90310-9.

[8] Dettman, J.R., Rodrigue, N., Aaron, S.D., Kassen, R. (2013) Evolutionary genomics of epidemic and nonepidemic strains of Pseudomonas aeruginosa. Proc. Natl. Acad. Sci. U. S. A. 110(52), 21065-70, http://dx.doi.org/10.1073/pnas.1307862110.

[9] Diaz, M.H., Hauser, A.R. (2010) Pseudomonas aeruginosa cytotoxin ExoU is injected into phagocytic cells during acute pneumonia. Infect. Immun. 78(4), 1447-56, http://dx.doi.org/10.1128/IAI.01134-09.

[10] Drancourt, M., Bollet, C., Carlioz, A., Martelin, R., Gayral, J.P., Raoult, D. (2000) 16S ribosomal DNA sequence analysis of a large collection of environmental and clinical unidentifiable bacterial isolates. J. Clin. Microbiol. 38(10), 3623-30.

[11] Gilmour, J.S.L. (1951) (C) 1951 Nature Publishing Group. Nature 168, 400-2.http://dx.doi.org/10.1038/168400a0.

[12] Gross, H., Loper, J.E. (2009) Genomics of secondary metabolite production by Pseudomonas spp. Nat Prod Rep 26(11), 1408-46, http://dx.doi.org/10.1039/b817075b.

[13] H. Rashedi., E. Jamshidi. (2005) Isolation and production of biosurfactant from Pseudomonas aeruginosa isolated from Iranian southern wells oil . Int. J. Environ. Sci. Tech. 2(2), 121-7.

[14] Höfte, M., Vos, P.D.E. (2006) Plant pathogenic Pseudomonas species. Plant Associated Bact., 507-33, http://dx.doi.org/10.1007/978-1-4020-4538-7.

[15] Irie, Y., O’Toole, G.A., Yuk, M.H. (2005) Pseudomonas aeruginosa rhamnolipids disperse Bordetella bronchiseptica biofilms. FEMS Microbiol. Lett. 250(2), 237-43, http://dx.doi.org/10.1016/j.femsle.2005.07.012.

[16] Kolyva, A., Karakousis, P. (2012) Old and new TB drugs: Mechanisms of action and resistance. Underst. Tuberc. - New
Approaches to Fight. Against Drug Resist., 210-32, http://dx.doi.org/10.5772/30992.

[17] Li, Z.Y., Lang, S., Wagner, F. (1984) Formation and identification of interfacial-active glycolipids from resting microbial cells. Appl. Environ. Microbiol., 610-7.

[18] Lin, H., Huang, S., Teng, H., Ji, D., Chen, Y., Chen, Y. (2006) Presence of the exoU Gene of Pseudomonas aeruginosa Is Correlated with Cytotoxicity in MDCK Cells but Not with Colonization in BALB / c Mice $\square$ 44(12), 4596-7, http://dx.doi.org/10.1128/JCM.01531-06.

[19] Magalhães, L., Nitschke, M. (2013) Antimicrobial activity of rhamnolipids against Listeria monocytogenes and their synergistic interaction with nisin. Food Control 29(1), 138-42, http://dx.doi.org/10.1016/j.foodcont.2012.06.009.

[20] Mathee, K., Narasimhan, G., Valdes, C., Qiu, X., Matewish, J.M., Koehrsen, M., Rokas, A., Yandava, C.N., Engels, R., Zeng, E., Olavarietta, R., Doud, M., Smith, R.S., Montgomery, P., White, J.R., Godfrey, P.A., Kodira, C., Birren, B., Galagan, J.E., Lory, S. (2008) Dynamics of Pseudomonas aeruginosa genome evolution. Proc. Natl. Acad. Sci. U. S. A. 105(8), 3100-5, http://dx.doi.org/10.1073/pnas.0711982105.

[21] McClure, C.D., Schiller, N.L. (1992) Effects of Pseudomonas aeruginosa Rhamnolipids on Human Monocyte-Derived Macrophages. J. Leukoc. Biol. 51(2), 97-102, Doi: file://Z: References\Text Files\00000004093.txt.

[22] Miethke, M., Marahiel, M.A. (2007) Siderophore-based iron acquisition and pathogen control. Microbiol. Mol. Biol. Rev. 71(3), 413-51, http://dx.doi.org/10.1128/MMBR.00012-07.

[23] Mishra, S., Arora, N.K. (2012) Evaluation of rhizospheric Pseudomonas and Bacillus as biocontrol tool for Xanthomonas campestris pv campestris. World J. Microbiol. Biotechnol. 28(2), 693-702, http://dx.doi.org/10.1007/s11274-011-0865-5.

[24] Nguyen, T.T., Sabatini, D.A. (2011) Characterization and emulsification properties of rhamnolipid and sophorolipid biosurfactants and their applications. Int. J. Mol. Sci., 1232-44, http://dx.doi.org/10.3390/ijms12021232.

[25] O’Neill, J., By, C., Neill, J.I.M.O., O’Neill, J. (2015) Securing New Drugs for Future Generations: The Pipeline of Antibiotics. Rev. Antimicrob. Resist. (May), 42.

[26] Preston, G.M. (2004) Plant perceptions of plant growth-promoting Pseudomonas. Philos. Trans. R. Soc. Lond. B. Biol. Sci. 359(1446) 907-18, http://dx.doi.org/10.1098/rstb.2003.1384.

[27] Rahman, K.S.M., Rahman, T.J., McClean, S., Marchant, R., Banat, I.M. (2002) Rhamnolipid biosurfactant production by strains of Pseudomonas aeruginosa using low-cost raw materials. Biotechnol. Prog. 18(6), 1277-81, http://dx.doi.org/10.1021/bp020071x.

[28] Sato, H., Frank, D.W. (2004) ExoU is a potent intracellular phospholipase. Mol. Microbiol., 1279-90, http://dx.doi.org/10.1111/j.1365-2958.2004.04194.x.

[29] Sharma, D., Tyagi, J.S. (2007) The value of comparative genomics in understanding mycobacterial virulence: Mycobacterium tuberculosis $H 37 R a$ genome sequencing - A worthwhile endeavour. J. Biosci., 185-9, http://dx.doi.org/10.1007/s12038-007-0018-z.

[30] Shaver, C.M., Hauser, A.R. (2004) Relative contributions of Pseudomonas aeruginosa ExoU, ExoS, and ExoT to virulence in the lung. Infect. Immun. 72(12), 6969-77, http://dx.doi.org/10.1128/IAI.72.12.6969-6977.2004.

[31] Soberón-Chávez, G., Lépine, F., Déziel, E. (2005) Production of rhamnolipids by Pseudomonas aeruginosa. Appl. Microbiol Biotechnol., 718-25, http://dx.doi.org/10.1007/s00253-005-0150-3.

[32] Soberón-Chávez, G., Lépine, F., Déziel, E. (2005) Production of rhamnolipids by Pseudomonas aeruginosa. Appl. Microbiol. Biotechnol., 718-25, http://dx.doi.org/10.1007/s00253-005-0150-3.

[33] Strateva, T., Yordanov, D. (2009) Pseudomonas aeruginosa - A phenomenon of bacterial resistance. J. Med. Microbiol., 1133-48, http://dx.doi.org/10.1099/jmm.0.009142-0.

[34] Walker, T.S., Bais, H.P., Déziel, E., Schweizer, H.P., Rahme, L.G., Fall, R., Vivanco, J.M. (2004) Pseudomonas aeruginosa-plant root interactions. Pathogenicity, biofilm formation, and root exudation. Plant Physiol. 134(1), 320-31, http://dx.doi.org/10.1104/pp.103.027888.

[35] [35]Wehmhöner, D., Häussler, S., Tümmler, B., Jänsch, L., Bredenbruch, F., Wehland, J., Steinmetz, I. (2003) Inter- and intraclonal diversity of the Pseudomonas aeruginosa proteome manifests within the secretome. J. Bacteriol. 185(19), 5807-14, http://dx.doi.org/10.1128/JB.185.19.5807-5814.2003.

[36] Woese, C.R., Fox, G.E. (1977) Phylogenetic structure of the prokaryotic domain: the primary kingdoms. Proc. Natl. Acad. Sci. U. S. A. 74, 5088-90, http://dx.doi.org/10.1073/pnas.74.11.5088. 